\title{
High performers in complex spatial systems: a self-organizing mapping approach with reference to The Netherlands
}

\author{
Karima Kourtit • Daniel Arribas-Bel • \\ Peter Nijkamp
}

Received: 26 August 2011 / Accepted: 24 November 2011 / Published online: 21 December 2011 (C) The Author(s) 2011. This article is published with open access at Springerlink.com

\begin{abstract}
This paper addresses the performance of creative firms from the perspective of complex spatial systems. Based on an extensive high-dimensional database on both the attributes of individual creative firms in the Netherlands and a series of detailed regional facilitating and driving factors related, inter alia, to talent, innovation, skills, networks, accessibility and hardware, a new methodology called self-organizing mapping is applied to identify and explain in virtual topological space, the relative differences between these firms and their business performance in various regions. It turns out that there are significant differences in the spatial and functional profile of large firms vis-à-vis SMEs across distinct geographical areas in the country.
\end{abstract}

JEL Classification $\mathrm{M} 1 \cdot \mathrm{M} 19 \cdot \mathrm{M} 2 \cdot \mathrm{M} 20 \cdot \mathrm{M} 21 \cdot \mathrm{Q} 5 \cdot \mathrm{Q} 56 \cdot \mathrm{R} 1 \cdot \mathrm{R} 10 \cdot \mathrm{R} 11 \cdot \mathrm{R} 12 \cdot$ $\mathrm{R} 15 \cdot \mathrm{R} 30$

\section{The complex space-economy}

The space-economy-with its myriad of actors, regions and interwoven networksexhibits a dynamic constellation that is both volatile and resilient. It comprises complex feedback systems that may break or reinforce spatial equilibrium forces

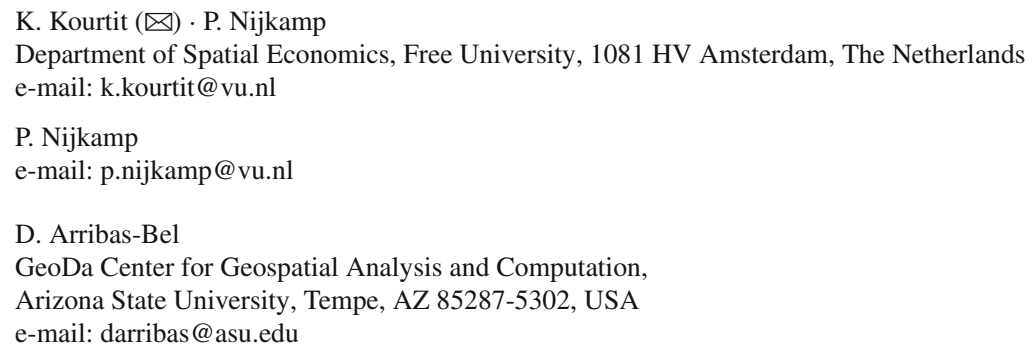


(Reggiani and Nijkamp 2009). The new innovation theory (Acs et al. 2002) has clearly demonstrated that innovative and creative firms ${ }^{1}$ are key actors in the economic change and transformation process of cities and regions. The interface between the business performance of individual firms and the socio-economic development of cities and regions calls for a thorough analysis of complex spatial systems, with due attention to the dynamic drivers of, and effects on, balanced regional development (van Geenhuizen 2007; Kourtit et al. 2011a).

Innovativeness and creativeness have become pivotal concepts in the modern regional development literature. Regions and firms appear to form a complex spatial-economic architecture that may be subjected to dynamic evolution and resilience. But which firms are responsible for the rapid spatial dynamics? And which firms are key actors in regional innovation systems? In the present study, we adopt the proposition that it is the best-performing firms that generate a maximum contribution to regional development. But at the same time, a reverse causality has to be taken into consideration, since regional moderator variables can also act as attraction forces for successful or high-performing firms.

The present paper investigates on an empirical basis whether localized concentrations of economic activity will yield the advantages and/or disadvantages, as predicted by the literature, for creative-often high-tech—business activities and/or firms, with an empirical focus on regions in the Netherlands. We will address in particular the spatial context in researching the determinants of economic development. Our research tends to highlight the crucial importance of geographic location and industrial proximity for business performance of - mainly-high-tech firms ${ }^{2}$ in the creative sector.

The overarching analysis framework of this paper is based on a concept from the industrial organization and business management literature, viz. Strategic Performance Management (SPM), extended with relevant spatial concentration and proximity dimensions. In this respect, SPM is defined as 'the process where steering of the organization takes place through the systematic definition of mission, strategy and objectives of the organization, making these measurable through critical success factors and key performance indicators, in order to be able to take corrective actions to keep the organization on track' (de Waal 2007). The effectiveness of the process is defined as the achievement of financial as well as non-financial targets, the development of skills and competencies, and the improvement of customer care and process quality and innovation (de Waal 2007).

It is often argued that SPM may improve the firms' competitive advantages by anticipating the rapidly changing circumstances within the industry and may help to manage these changes, so as to overcome their growth constraints in order for them to effectively compete on local or global markets; to directly respond to the needs of customers and to provide new opportunities for utilizing innovations in their products

\footnotetext{
1 Creative firms normally belong to the innovative part of the industrial sector and tend to be rather competitive through their resilience and flexibility.

2 These firms operate in an extremely volatile, dynamic and uncertain business climate with continually changing technologies, markets, business strategies, and shifting consumer needs for products and services (fundamental transformation). They are engaged in development, manufacturing and distribution of high-tech products, technology transfer and consultation.
} 
and business processes. Consequently, our research adopts a localized concentration perspective on the determinants of business performance, and it ties in with the modern regional entrepreneurship literature.

The aim of our study is to associate well-defined SPM initiatives of individual firms in the creative sector-in particular, high-tech firms - with a broad array of regional background (both facilitating and driving) variables. This is a rather novel approach in the regional-economic and industrial business literature. Methodologically, we employ a recently development analysis technique in the complex systems literature, viz. self-organizing maps (SOMs), which belongs to the family of computational neural network analyses. This SOM approach will be utilized to explore the interface between business performance and regional moderator variables.

This study is organized as follows. Section 2 offers a brief presentation of some highlights from the literature on the creative industry-regions nexus, with a specialthough not exclusive-interest in the economic significance of the high-tech sector. In Sect. 3, the principles of the multivariate learning tool for analyzing complex systems and networks in our study, namely SOMs, are briefly described. Next, Sect. 4 is devoted to a description of the merger of data sets for our empirical analysis, by combining micro-based data on creative — mainly high-tech firms - in the Netherlands with a wealth of regional background variables. Section 5 focusses then on an in-depth presentation and interpretation of the empirical results, which also includes an integration of two mapping applications - one on regional growth drivers and another one on creative business firms-is presented. The results of some robustness checks are also described. The paper concludes with some retrospective and prospective remarks.

\section{Innovative firms as complex carriers of a creative economy}

The pivotal role of high-tech firms in creativity and innovation has been widely acknowledged and documented in the economic and entrepreneurship literature (see, e.g., Pavitt 1990; Berry and Taggart 1996; Capello 2002; Felsenstein 2002; Moreno et al. 2005; Alecke et al. 2006; Oakey 2007; Cooper and Park 2008). Such firms represent a powerful medium for inducing and encouraging the creation of new businesses and jobs and are a promising source of wealth for society, and form an important element of a vital urban or regional economy (see e.g., Florida 2002, 2004; Lee et al. 2004; McGranahan and Timothy 2007).

Several regions and cities_-such as Paris, Berlin, Vienna, Dubai, London, Prague, Amsterdam, Sydney, Manchester, Glasgow, Rome, Milan, Melbourne, Toronto, Tokyo, Madrid, Barcelona, Lisbon, Dublin, New York, Austin, and Newcastle-with a highly concentrated creative production system, an original entrepreneurial spirit, a flexible institutional system, and modern lifestyles and consumption levels have undergone significant structural changes in recent years. Such creative or smart areas normally have a strong knowledge and innovation base (Kourtit et al. 2011b).

In today's open world driven by global competiveness, many regions and cities are forced to turn into multifaceted business and residential concentrations-with an unprecedented innovative, creative, and cultural diversity-which are competitive assets to improve the socio-economic performance of these areas, and to shape 
a spectacular new and diverse urban design and lifestyle for accelerated economic growth (Jones-Evans and Klofsten 1997; Bommer and Jalajas 2002). They are challenged to form a 'Creative Geographic Space' by novel governance models, and to develop new ideas to implement an effective strategy for public interventions at the local level by encouraging the development of creative industries and consequent economic growth (Kourtit et al. 2011c). The role of creativeness in geography can be traced back to earlier writings of Tornqvist (1983) and Andersson (1985) in the 1980s, but in recent years has been revisited in the work of Landry (2000) and Florida (2002). This new paradigm has prompted a certain hype around the concept of a creative, open and globalizing world with social, cultural, and creative urban environmental factors and mechanisms that are diverse and dynamic (Florida 2003; Forte et al. 2006; Peck 2005; Matheson 2006; Olfert and Partridge 2011). Creative and innovative attitudes and opportunities - for instance, by being open and communicative-are considered to be a sine qua non for a flexible response to the increased global and challenging business world, that is able to meet the need for immediate adaptation to dynamic or volatile market changes.

The spatial-temporal complexity leads to a new 'spatial imperative': modern regions and cities must attract, retain, and even nurture, highly mobile and (global) creative and innovative firms and talents (the 'pluriformity' approach), as their aggregate efforts become the primary drivers that will deeply affect the ground rules for securing economic development and the competitive advantage of modern regions and cities and their networks (Glaeser 2004; Muñiz et al. 2010; Nijkamp 2008; Peck 2005; Shea 2004; Sonis and Hewings 1998). To manage their regional or urban economies and strengthen their international position, many regions and cities have to compete in fiercely contested arenas for 'creatives'-individuals, firms, and organizationsas a new increasingly pervasive (business) development policy strategy in order to attract or generate highly specialized creative and knowledge sectors (see Bayliss 2007). These observations inform competent stakeholders how to operate within the new creativity paradigm in favor of creative firms and talents, both domestically and internationally (Bruinsma et al. 2009), and highlight the conditions for success in the creative economy. It goes without saying that employment opportunities, and enterprises in particular, may play a central role in creating a new urban or regional vitality (Bellini et al. 2008; Lee et al. 2004; Nijkamp 2009). Clearly, with the increasing interest in high-tech firms, the need to properly understand the nature of their location behavior and decisions has become of paramount importance across a wide range of stakeholders.

Regional governments, decision-making bodies at local levels, and leading firms in the area concerned are thus changing their existing economic and productive positions (Porter 1990; van den Berg 2001) by providing the most promising and profitable business environment (Porter 2002). They may ensure an efficient design and use of smart spatial amenities, such as local infrastructure, urban quality of life in the region concerned, and availability of various capital resources (e.g., qualified labor) used in the production of innovative products and/or services. A key factor is that both informal and formal knowledge spillovers among all actors and stakeholders occur in these regions and cities (Jacobs 1969; Duranton and Puga 2003), thus creating sustainable economic development and growth (Porter 2002). 
The observations made above prompt the question concerning the relationship between the spatial dimension (geographic attributes) and regional factors, on the one hand, and business performance by individual entrepreneurs on the other. In recent years, we have also witnessed a reorientation of the research and policy interest of international institutions (e.g., the World Bank) toward the interaction between business activities and localization. Although there is a common agreement on the interdependence between local and regional environmental factors and the business performance of firms and their economic activity (e.g., formation, survival, functioning, and growth), many studies that pay attention to this issue are based mainly on anecdotal evidence and offer mainly case study observations or in-depth interviews with a few key-players. In various cases, however, they come up with mutually contrasting conclusions, while solid empirical quantitative research leading to generalization is scarce. Consequently, many research questions still remain a puzzle, both theoretically and empirically. This suggests that more solid research on this topic is definitely needed in order to better understand the interplay between the firm's performance and its geographic environment. Our research provides offer a framework for addressing the mutual interplay between the business performance of creative, high-tech firms in the Netherlands and geographical amenities at local and regional scales that are a moderator factor for economic development.

Our study uses a GIS approach with respect to various individual and spatial attributes, in combination with multivariate statistical tools. These tools are deployed in order to highlight the results of a SOM analysis that is applied to a multi-dimensional data set in order to compare the performance of the firms under consideration (240 respondents; 60 firms in total). This complex systems approach allows us to assess systematically the regional patterns of spatial activities, and to integrate and provide relevant information with a geographic component in order to enhance our insight into critical business and planning decisions for both localization and business performance. Section 3 will be devoted to a brief introduction to, and exposition on, SOMs.

\section{The self-organizing map approach}

The Self-Organizing Map or $\mathrm{SOM}^{3}$ (Kohonen 2001) is an algorithmic approach that is associated with the family of unsupervised computational neural networks (for a general overview of neutral networks, see Fischer 2001). It is essentially a special type of neural network, as it is based on a set of nodes or neurons that are connected to each other through topological relationships, while it is unsupervised because the observations are not previously labeled as pertaining to one or another category, but rather such a categorization is unknown. It was originally developed in the 1980s with

\footnotetext{
3 The term "self-organizing" in this context should not be confused with other 'self-organizing' concepts in the literature (see, e.g., Krugman 1996; Kumar et al. 2007; Lung 1988). In an economic context, this concept refers to interactive behavior of economic agents and their effects on the mechanism of the economy, while in our case, self-organization refers to the learning process that the algorithm employs to make it possible for observations to locate near to similar ones and distantly from more different ones in the output space.
} 
the purpose of explaining the complex organization of the brains functions (see for an overview Kohonen and Honkela 2007; Arribas-Bel et al. 2011); the primary objective was to reduce large and high-dimensional data sets, in terms of both the number of dimensions (projection) and the amount of initial observations (quantization), while maintaining the relevant information and presenting it in an understandable way for the human brain in order to uncover hidden patterns. Although its popularity has increased greatly over the years, and it has been used in many fields beyond those for which it was originally conceived, it has only been recently that the social sciences have become aware of its research potential. Certainly, the increasing availability of larger and more complex data sets describing socio-economic phenomena is bringing to the social sciences what (Skupin and Agarwal 2007) call 'truly n-dimensional' data. It is also making increasingly explicit the need for different tools that complement traditional statistical tools and that help to fully exploit the potential of such new data bases. It is in this context that the term 'data mining' fits, and where the SOM, as one of the components of this new toolkit, gains the power to shed new light on, and uncover, interesting patterns in complex relations. Recent attempts to explore this methodology in the social sciences include studies by Skupin and Hagelman (2005) and Spielman and Thill (2008) in socio-demographics; Yan and Thill (2009) in airline flows; Arribas-Bel et al. (2011) on urban sprawl in Europe; Kourtit et al. (2011b) on smart cities. Agarwal and Skupin (2007) offer a collection of interesting applications in the field of GIScience.

The output of a SOM is a network of neurons that are interconnected by topological relationships and that are usually represented by hexagons, implying therefore that the normal neuron (i.e., not on the edge) will have six neighbors and will thus be connected to six other neurons. Because of the particular characteristics of the algorithm, this space that is created preserves the statistical properties of the original sample, although it contains only two dimensions, as opposed to the (usually larger) original dimensionality. The SOM thus creates a statistical space onto which the original observations may be mapped, thus making topological what in origin was statistical. It is important to stress the fact that the output of the SOM is a separate space that contains the statistical properties of the original observations and that allows them to be mapped onto its surface, but that is not composed by them. In this context, dissimilarity between observations is translated into distance within a SOM: similar observations will tend to be close to each other, whereas distinct ones will be more distant. Although the SOM has been compared with other statistical techniques, such as principal components and factor analysis, or clustering algorithms, such as k-means or hierarchical clustering, according to Yan and Thill (2009) there are clear advantages inherent in this approach: the learning nature of the algorithm that avoids no recovery, continuing to compare and use information from every observation even after they are first assigned to a neuron; the use of the distance of each input from all neurons as opposed to only the nearest one; the fact that the SOM is a combination of both data quantization and data projection; and the visualization opportunities that it offers. Among all of these, the latter one has greater implications for the present paper, since it is the ability to represent in a visual and intuitive way the underlying statistical properties of high-dimensional data sets that makes the SOM a suitable tool to unfold complexity into understandable patterns that enhance understanding. 
Although the underpinnings and computational challenges involved are quite tricky, the general intuition of the SOM algorithm is rather simple. ${ }^{4}$ We begin by defining the topology we will work with, that is, the number of neurons, as well as the neighborhood relationships (typically hexagonal) and their arrangement (squared, rectangular). Once the original set-up is ready, each neuron needs to be assigned a vector of as many dimensions as the original data set; initially, the values could be random, as the properties of the sample are entirely transferred through the algorithmic process. The training phase then starts by presenting the observations to the network in a sequential fashion; for each of them, we try to find the best matching unit (BMU), that is, the neuron for which the distance (usually, Euclidean) is minimized. At this point, both the BMU and its neighbors are modified to become closer, although the extent of the modification depends on the distance of each neuron to the BMU: the latter gets a significant 'update' of its values, while neurons further away get smaller ones. It is important to stress that the BMU should be partially, not completely, modified to match the observations. This, combined with the repetition of the steps many times (in the order of hundreds of thousands), is at the heart of the self-organizing and the learning nature of the algorithm. In order to facilitate the convergence of results, the number of neighbors (defined by a neighborhood function) and the extent of adjustment (learning rate) decrease over the training phase, so that at the end of the process very few neurons beyond the actual BMU are slightly modified. As mentioned above, this is repeated a large amount of times, yielding at the end a trained network, one in which the values of the nodes are no longer random, but reflect the statistical properties of the original data set used.

A trained network may be used for in-depth analysis of, for instance, underlying patterns. Although there are several ways to extract information and interact with a SOM, two of the main ones are used in this paper. The first consists of simply mapping the original observations onto the statistical space created. In the same way as during training, we can link the input data with the output space by assigning them to their BMUs. This locates the original observations in different areas, or regions, of the SOM, according to their characteristics, thus creating a statistical topology that quickly allows a visualization of more abstract relationships and might reveal interesting patterns in the data.

A further enhancement of this technique that we also make use of in this paper consists of mapping an 'external' variable onto the SOM. In this case, the BMUs are not only represented, but also an additional dimension is introduced by using different colors or some other symbology based on a variable not used for training. This allows us to observe trends in the association between the variable and those variables used to feed the algorithm, not only in a global way (as in correlation coefficients, for example), but in a more fine-grained manner, which also uncovers individual patterns. Another way to analyze a SOM relates to what are called component planes. This approach is a visualization of the trained network rather than a link to the original observations. It basically consists of mapping in a sort of choropleth the values of one of the dimensions of the neurons to see where high and low values are located, and

\footnotetext{
4 This article only presents the general idea of the basic version of the SOM algorithm; for a complete and rigorous treatment, the reader is referred to Kohonen (2001).
} 
thus be able to characterize different regions within the SOM. One can do that for each of the variables used in the training, thereby getting a better insight into what different regions mean, and what are the underlying characteristics. When combined with the BMUs, this allows a characterization of the observations through their spatial location within the SOM. In Sect. 5, we present some interesting SOM results from an application to the Netherlands, after a concise description of our database in Sect. 4.

\section{Description of high-dimensional data sets on firms and regions}

This section describes the details of our database and the multivariate methodology employed. Our study combines data from different sources to represent a microbusiness perspective on the determinants of the firms' performance and their links with regional entrepreneurship and socio-economic moderator variables at a detailed spatial level. The data were partly provided by, among other, Statistics Netherlands (CBS), and partly obtained from detailed interviews with representatives of Dutch firms (from which both location and performance factors were collected).

Our empirical approach is based on original micro- and macro-scale data. At the macro-level, we rely on very detailed and extensive regional and location-specific data at a municipal and regional level which can mainly be aggregated to a NUTS-3 level (so-called COROP regions in the Netherlands) and later on to a provincial level. Clearly, the regional perspective (a source of differentiation for business firms) is critical to assess how and to what extent strategic business objectives included in SPM and value creation by a firm are actually achieved in the entire value chain of the local business network in which they operate. Otherwise, a firm might end up working with only one part of the value chain, while the total value might actually accrue to other firms really taking all the benefits. In the complex force field of business strategies and individual driving forces that together make up the critical success factors (CSFs) of a firm, it is important to stress that the performance of a firm is not only determined by its own decisions, but also by its local business environment. Therefore, it is necessary to zoom in on the regional or local level, where all economic activities come together, and where all things are happening that lead to effective socio-economic action and achievement.

Many spatial moderator data in our research appeared to be available on a consistent basis for 40 Dutch NUTS-3 regions and 467 municipalities for the year 2008. The data set contains geographic concentrations of the relevant variables, which comprise inter alia innovative socio-economic activities, business operations, and environmental and contextual factors at the regional or local level. All these data are associated with the spatial-economic and social environment (for a general exposition on these concepts, see also Glaeser 2004; Shea 2004). The total data set comprises 410 distinct variables or indicators at a regional or local scale (see also Appendix A). Unfortunately, some variables were only available at the provincial level in the Netherlands (in total, there are 12 provinces), so that we were forced consistently to aggregate all data from municipal and COROP levels to the provincial level, by using GIS interface methods. A provincial map of the Netherlands is given in Fig. 1.

As well as having a wealth of multifaceted data at a regional scale, we were also able to obtain detailed micro-based information on a multiplicity of characteristics - in line 


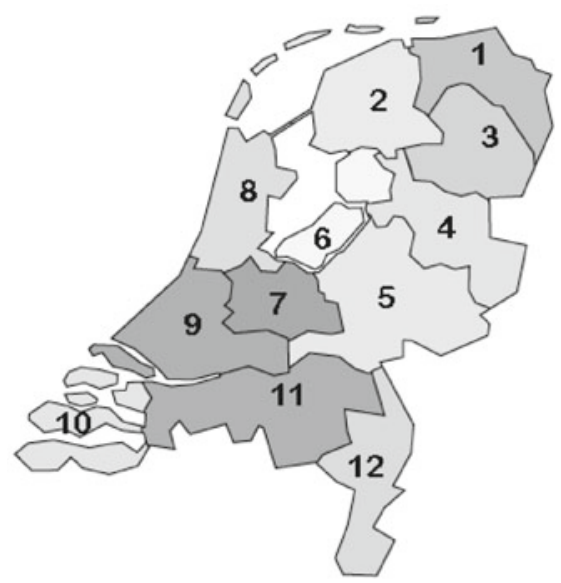

12 provinces of the Netherlands:

1. Groningen

2. Friesland

3. Drenthe

4. Overijssel

5. Gelderland

6. Flevoland

7. Utrecht

8. Noord-Holland

9. Zuid-Holland

10. Zeeland

11. Noord-Brabant

12. Limburg

Fig. 1 Map of the 12 provinces of the Netherlands. Source: http://www.digital-dreams.nl/realdutch/ images/provincies.gif

with the SPM methodology — of 60 firms (19 large firms and 41 SMEs) in the creative sector (in particular, in the high-tech sector) in the Netherlands, in which SPM played a role. These data were obtained by administering extensive face-to-face interviews with an average of 4 key managers per firm.

These individual firm data are related to both output and input performance characteristics, as well as to motivational and driving forces that are decisive for turning the firm into a high-performance firm, a so-called high performer or exceptional champion. In order to trace the opportunities and barriers of the business performance among these firms in the Netherlands, we had to organize an in-depth field survey in our search for such exceptional firms with a peak performance.

As a prior broad literature search did not create a solid basis for a satisfactory and validated questionnaire to obtain verified and systematically structured information from the firms on their critical performance success conditions and indicators that reflect innovations in a competitive economic system driven by profit motives, a self-composed 'statement questionnaire' was used. The participating companies, all from the private sector, were selected on the basis of two dominant criteria: namely whether they operate in the creative industries, ${ }^{5}$ and had implemented and used SPM measurement systems. ${ }^{6}$ The use of SPM measurement systems helps us in further discriminate between low and high performing organizations (see previous works of de Waal et al. 2009; Kourtit and de Waal 2009; Kourtit et al. 2011a). The performance statements in the questionnaire were next identified from the broad literature available

\footnotetext{
5 Creative industries in our study refer to a range of economic activities in sectors such as advertising, architecture, arts, tourism services, design, fashion, film, R\&D, high-tech, games, and media.

6 The selection mechanism of these firms was partly based on the information from Dutch industrial branch organizations on the management profile of specific firms and partly on previous expert contacts established with them, so that easy access was facilitated. Consequently, a reasonable degree of representativeness may be expected.
} 
(indicators were converted into statements and presented to the interviewees) and were then re-formulated so that the interviewees had to give a rating on a 5-point Likert scale, varying from ' 1 = not at all' (i.e., 'we did not experience the SPM advantage' at all) to ' 5 = very strong' (i.e., 'we experienced the SPM advantage very strongly). The interviewees were also asked whether they had experienced any measurable disadvantages from the implementation and use of the SPM measurement system in their organization $^{7}$ (for details, see also Kourtit and Nijkamp 2011).

The questionnaire was first tested at the company level, after which some adjustments were made in the formulation of several questions. In total, 240 representative people (organizational staff members, key functionaries) of 60 creative business firms (19 large firms and 41 SMEs) were interviewed. After the interviews, the interview reports were sent to the interviewees for confirmation of their responses. After the interviewees had approved the interview reports, the answers given were averaged for each company so as to get a representative robust picture for each firm.

The precise geographical coordinates of these firms were, of course, known. And therefore, it was possible to assign the location of each individual firm unambiguously to the regional level employed in our study. Next, spatial GIS-oriented statistical analysis was applied to integrate separate and disaggregated original micro- and macro-scale data formats to give visibility (to uncover a variety of information) and to identify geographically discriminating factors in the firms' performance.

In order to (i) avoid the collection and use of an overwhelming amount of unstructured spatial data (which initially yielded a wealth of information on 410 variables in 467 municipalities and/or 40 regions), (ii) get a better insight into the critical success factors for the business performance of the 60 Dutch firms concerned, and (iii) obtain an informed idea about the most crucial characteristics and achievements of the different regions and about the firms' performance in our subsequent statistical analysis, the long list of variables was systematized and summarized by means of a clustered presentation in eight groups (see Fig. 2), which contains all available variables. These groups are as follows: Creative Capital (CC), Human Capital (HC), Economic Capital (EC), Knowledge Capital (KC), Social Capital (SC), Cultural Capital (CLC), Connectivity \& Infrastructure Capital (CFC), and Technological Capital (TC). Similarly, the SPM data of the individual firms were also clustered according to three main characteristic groups, viz. High Result Orientation (HRO), High Quality Business (HQB), and Better Understanding Strategy (BUS). In this way, it was also possible to use at a later stage a systematic data reduction method based on Principal Component Analysis (PCA). We are now able to offer a compact, systematic picture of the general microand macro-scale data, as depicted in Fig. 2. We refer to Appendix A for more details.

This conceptual information framework was used in our SOM analysis in order to extract significant and systematic patterns in firm performance and spatial drivers, so as to understand better the linkages between geographic business environments and

\footnotetext{
7 To increase internal and external validity, the questionnaire employed also offered the opportunity to fill in other alternative and extraneous (dis-) advantages the interviewees had experienced, from the implementation and use of the SPM measurement system in their organization compared to previous years without the implementation of SPM. No prior selection of (sub-)sectors was made in order to allow for more generalization of the research results.
} 


\section{Composition of the Data base}

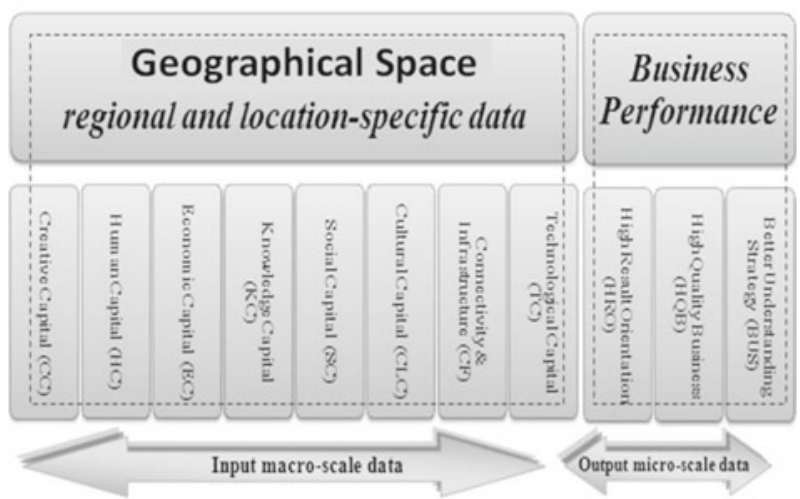

Fig. 2 Structure of the systematic database for Dutch regions and firms

the firms' strategic options and performances - and also to assess location decisions in line with their business strategy - at both the geographical level and the level of firms. By using this approach, we are able to identify systematic patterns from the large amount of data on the many variables available, and to gain insight into how firms relate to each other in a high-dimensional data context, for example, by judging whether the best geographic location of a firm is uniquely dependent on its own business strategy (including SPM). The methodology used is based on the SOM approach described above; its results are presented in Sect. 5 next.

\section{SOM results on firm performance and regional drivers in the Netherlands}

\subsection{Location factors and spatial distribution of firms}

As a first step in our exploration of spatial patterns of creative Dutch firms, we relate geographical firm location to regional factors. The main interest is first to explore how firms located in different regions relate to each other, based on the characteristics of such regions. We approach this question from a SOM perspective, which creates a statistical space in which the provinces of the Netherlands (and subsequently, firms) are mapped according to their regional characteristics, rather than to their geographical coordinates.

Figure 3 represents the two main spaces coming together in the SOM analysis: on the left-hand side (a) of Fig. 3 we have a geographical map ${ }^{8}$ of the Dutch provinces, while on the right-hand side (b) we have a topological virtual map obtained from a SOM network trained by using all the regional factors explained in Sect. 4. In the latter map, unlike its left counter-part, the position of the elements is not based on physical

\footnotetext{
${ }^{8}$ For statistical reasons, i.e. absence of firm data on Friesland and Flevoland, these two provinces are left out of consideration in Fig. 3a and subsequent maps.
} 


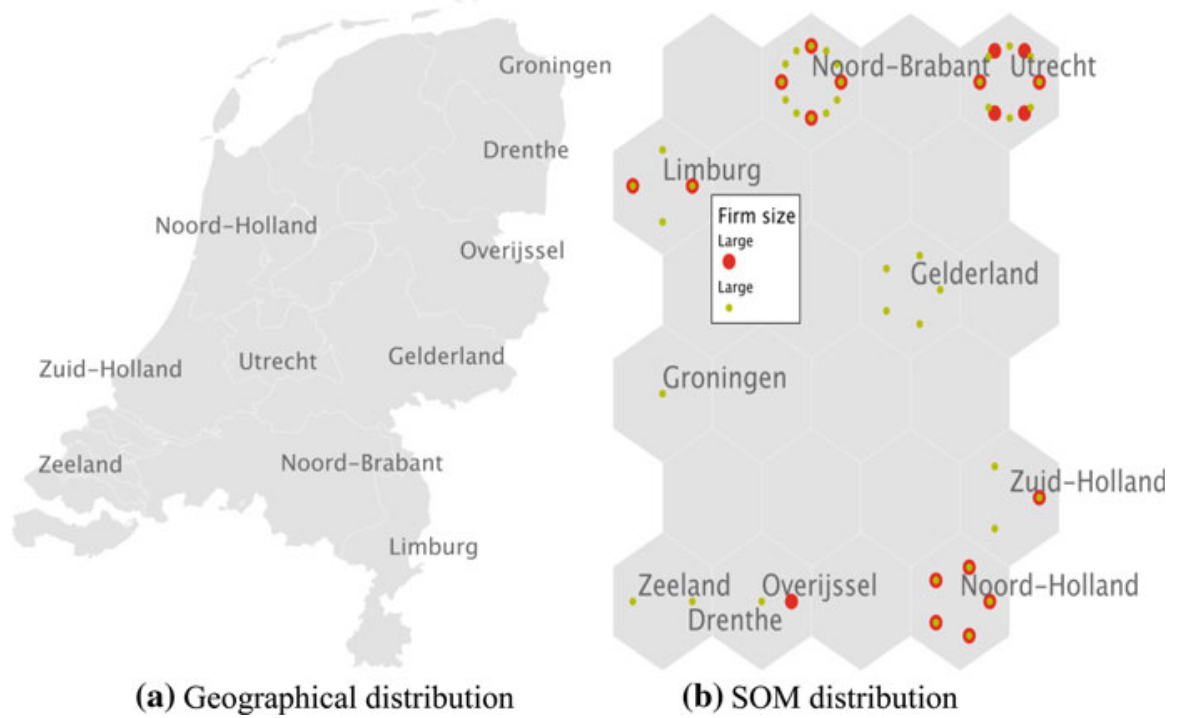

Fig. 3 Firm distribution across geographical and statistical space

geography but on statistical associations. Thus, distance in Fig. 3b implies dissimilarity: the more distant two observation points are, the more different characteristics they have, and vice versa. Following this reasoning, we can now make comparisons between the geographical and the statistical maps of the Netherlands, and see how, for instance,- - despite the physical distance between the provinces of Zeeland and Drenthe-their characteristics are very similar, which makes them statistical neighbors. We can also observe how, in other cases, geography is a good representation of statistical characteristics: Noord (North)-Holland and Zuid (South)-Holland are neighbors, both in the real world and in a SOM sense; a similar situation applies to Noord (North)-Brabant, Utrecht and Gelderland.

Since in this stage, the SOM has been trained using the regional characteristics, it allows a direct mapping of the provinces through their best matching units (BMUs), as explained in Sect. 3. Moreover, since we know where each firm is located, we can proceed and link the set of firms to each province neuron, obtaining, by extension, the position of each firm within the new statistical space created. As such, Fig. 3b also offers a first visualization of the firms under consideration. Larger dots represent large firms in the data set, while smaller dots stand for small (SME) firms. ${ }^{9}$ As can easily be grasped from the figure, the distribution is fairly unequal, both between large and small firms as well as location-wise: while regions such as Groningen only have one (small) firm, others like Noord-Brabant have four large ones and 12 of a small size. The performance itself of all firms concerned is now further investigated in Sect. 5.2

${ }_{9}$ All the figures in the paper are available in color in the digital version, to be found online. 


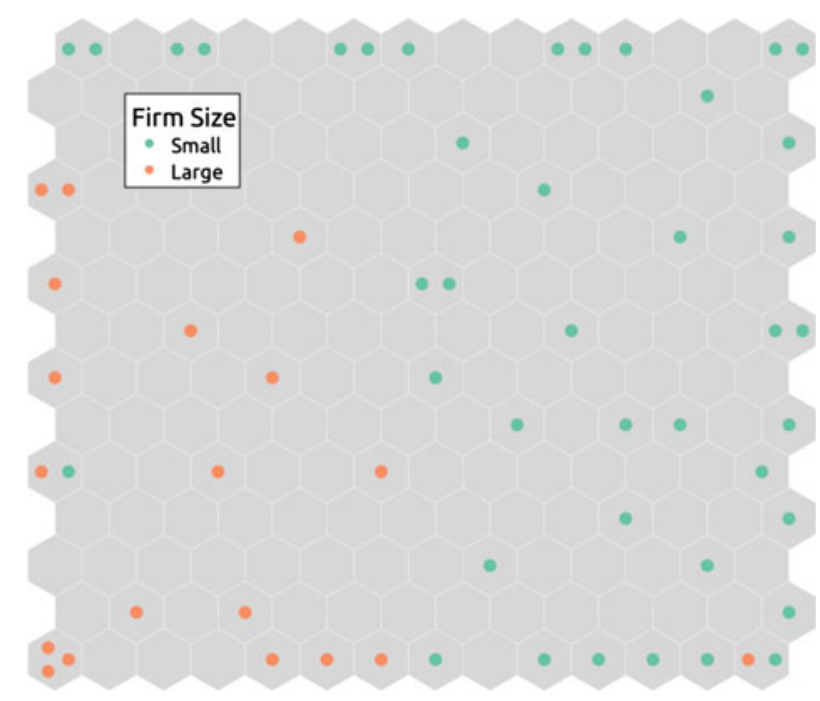

Fig. 4 Distribution of firms' size and characteristics across the SOM

\subsection{Analysis of firm performance}

Notwithstanding the interesting patterns that arise from comparing the geographical and statistical distribution of provinces and firms, the main interest of our analysis is in the study of firm performance based on the SPM principle. In this context, we interpret this concept in a high-dimensional manner, understanding that the performance of a firm is composed of many factors, and thus that there is not only one form of high (or low) performance, but different kinds of performance. It is important to clearly highlight this framework, as this is quite different from the one typically used in the literature in which, in order to deal with a high-dimensional concept, an index or score variable is defined, which collapses all the variables that capture every aspect into a composite indicator that is further used in the analysis. Although the latter approach maybe useful, in the present case, we aim to focus on, and to make explicit, the complexity inherent in the nature of the firms' performance with a spatial distribution, and to look at systematic patterns that may emerge within such a complexity, which would otherwise probably not have been noticed had we used a composite measure. Nevertheless, we will return to the idea of summarizing performance in one score variable at the end of this section (Sects. 5.4 and 5.5), where we try to build a bridge between both perspectives.

The main tool we use to accomplish our purpose is the SOM network whose results are displayed in Fig. 4. Since the rest of the section revolves around this device, it is important to gain an adequate understanding of its composition. The network is trained using the performance data at the firm level presented earlier in Sect. 4. We can interpret this as a spatial representation of the firm performance: in other words, as a map of the statistical characteristics of the data set employed. Onto this map, it is possible to locate each of the input the firms used in our analysis, according to 
their values for each variable considered. The figure displays the position of the firms, where one group of firms may be very similar in terms of performance, while others are as different as the sample gets.

An interesting question to ask now is whether there is any systematic pattern across the configuration of firms within the statistical map displayed in Fig. 4. In other words, we want to explore whether, besides having similar profiles of performance, firms located near to each other share similar characteristics with regard to other values. It should be noted that Fig. 4 also displays an additional layer of information by using different colors to mark the location of each firm. The resulting pattern appears to be striking in that it almost implies a perfect split of the SOM into two regions: one populated by large firms in the middle and lower left part; and the other filled with small ones across the rest of the map. This indicates that, since they are located in the same region of the SOM, large firms tend to have similar profiles of performance, while the same is true for small firms. This result suggests a substantial influence of the variable firm size (i.e., large and small) on the various criteria of business performance in an SPM context.

\subsection{Analysis of location and urbanization}

Besides firm size (large vs. SMEs), we now also consider two other geographically oriented variables of the firms concerned in order to analyze how they relate to performance: their geographical location in the Netherlands and the level of urbanization in the area where they are located. In the first case, we are trying to answer the question whether firms geographically located in the same province are mapped onto the same topological area of the SOM and thus have a similar performance; in the second case, we look for co-location patterns of firms established in places with similar degrees of urbanization. The technique we use is very similar to the one used for firm size: each category is assigned a color and firms are colored based on the category to which they belong in the variable of analysis. The maps in Fig. 5 display: (a) the distribution of the different provinces and (b) the level of urbanization across the firm' performance space of the SOM.

In both cases, the patterns are not nearly as clear as for firm size. Part of this relates to the fact that for both variables there are more categories (multiple provinces and various urbanization levels, respectively) than in the case of firm size (only two, big and small), which makes it harder from a cognitive perspective to visually detect patterns, even if they were to exist. To work around this difficulty, it would be desirable to switch from purely visual techniques to more analytical measures that summarize in quantitative numbers the spatial patterns of the SOM. To cope with this issue, Spielman and Thill (2008) have proposed a simple measure (Disp) to calculate the dispersion of observations from one category across the SOM. The intuitive idea is to compare the average distance between the elements of the category to the global average distance between all observations of the SOM. In analytical terms this means:

$$
\text { Disp }=\frac{\bar{d}_{\text {subset }}}{\bar{d}_{\text {global }}}
$$




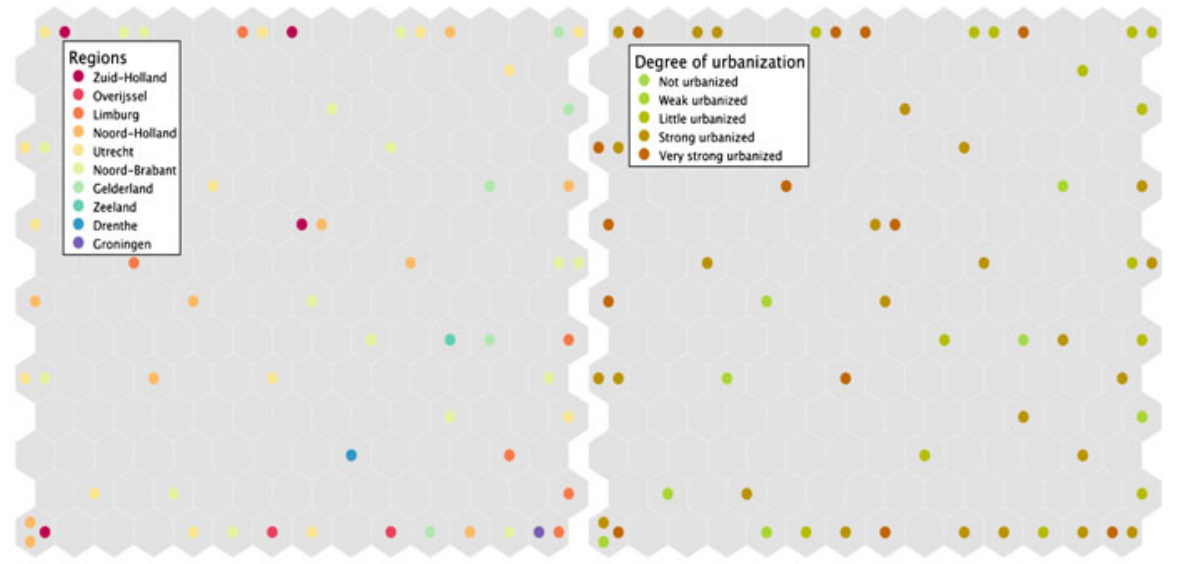

(a) Geographical location

(b) Urbanization

Fig. 5 Distribution of spatial variables across a performance-based SOM. a Colors associated with the following regions, in order of appearance in the legend: Zuid-Holland, Overjissel, Limburg, Noord-Holland, Utrecht, Noord-Brabant, Gelderland, Zeeland, Drenthe and Groningen. b Degrees of urbanization: not urbanized (lighest green), weak urbanized, little urbanized, strong urbanized, very strong urbanized (darkest brown) (color figure online)

where $d_{i j-\text { subset }}=\frac{1}{N_{\text {subset }}} \sum_{i_{\text {subset }}} \sum_{j_{\text {subset }}} d_{i j} ; d_{i j}$ is the distance between observation $i$ and $j$; and $d_{\text {global }}$ represents the version of $d_{\text {subset }}$ considering all the observations of the SOM. When Disp $=1$, the average distance between the elements (firms in this case) of the category concerned equals that of the global distance; however, when the index is smaller (greater) than 1, the observations in the subset of choice are, on average, closer (further) to each other, implying some degree of relative concentration (dispersion).

We will now use this measure to find out whether firms in the same province or with the same level of urbanization tend to be closer to each other, which would suggest that such variables are associated with particular types of performance. Tables 1 and 2 display the indices for each subset in both variables i.e. the provincial, and the urbanization level, marking with an asterisk those cases where the measure is below 1 , implying some degree of concentration. The measures are calculated for the complete set of firms (large and SMEs) as well as for the SMEs and the large ones separately. When all firms are considered, in the case of the provinces - although many score below 1-the difference is minor, except for Gelderland and Overrijsel; the numbers for urbanization do not differ very much, with only one category showing a value below 1 , but again above 0.9 . When we subdivide our set of firms by size, some more interesting patterns arise. Particularly, large firms from Limburg (0.63) and Utrecht (0.49) display a clear concentration in the SOM; also, the degree of urbanization among large firms is clearly ordered across the SOM, since all of them show indices clearly below $1(0.66,0.81$, and 0.53$)$. Although small firms show less distinct patterns, those in both weakly and very strongly urbanized areas also tend to locate in the same virtual topological region of the SOM. The main conclusion we may draw from this analysis is that, although in a global aggregate case we do not see clear 
Table 1 Dispersion measures for location

\begin{tabular}{|c|c|c|c|c|c|c|}
\hline \multirow[t]{2}{*}{ Firms located in } & \multicolumn{2}{|l|}{ Total } & \multicolumn{2}{|l|}{ Large } & \multicolumn{2}{|l|}{ SMEs } \\
\hline & Score & Nr. firms & Score & Nr. firms & Score & Nr. firms \\
\hline Groningen & - & 1 & - & - & $0.000000 *$ & 1 \\
\hline Zeeland & $0.7203 *$ & 5 & - & - & $0.000000 *$ & 1 \\
\hline Noord-Brabant & $0.9637 *$ & 16 & $0.848567 *$ & 4 & $0.939080^{*}$ & 12 \\
\hline Noord-Holland & $0.9903 *$ & 10 & $0.703364 *$ & 5 & 1.159810 & 5 \\
\hline Zuid-Holland & 1.0625 & 4 & $0.000000^{*}$ & 1 & 1.308831 & 3 \\
\hline Drenthe & - & 1 & - & - & $0.000000^{*}$ & 1 \\
\hline Overijssel & $0.3658 *$ & 2 & $0.000000^{*}$ & 1 & $0.000000^{*}$ & 1 \\
\hline Limburg & $0.9444 *$ & 6 & $0.633554 *$ & 2 & $0.734547^{*}$ & 4 \\
\hline Utrecht & 1.0654 & 14 & $0.485365^{*}$ & 6 & 1.249930 & 8 \\
\hline Gelderland & - & 1 & - & - & $0.978324 *$ & 5 \\
\hline
\end{tabular}

Asterisks are included for scores less than one, indicative of concentration

Table 2 Dispersion measures for urbanization level

\begin{tabular}{|c|c|c|c|c|c|c|}
\hline & \multicolumn{2}{|l|}{ Total } & \multicolumn{2}{|l|}{ Large } & \multicolumn{2}{|l|}{ SMEs } \\
\hline & Score & Nr. firms & Score & Nr. firms & Score & Nr. Firms \\
\hline None & - & 1 & - & - & $0.000000 *$ & 1 \\
\hline Weakly & 1.0649 & 7 & $0.664623 *$ & 5 & $0.609638 *$ & 2 \\
\hline Little & $0.9204 *$ & 14 & $0.000000 *$ & 1 & 1.067805 & 13 \\
\hline Strong & 1.0611 & 25 & $0.811486^{*}$ & 7 & 1.016778 & 18 \\
\hline Very strong & 1.0249 & 13 & $0.530498 *$ & 6 & $0.824621 *$ & 7 \\
\hline
\end{tabular}

Asterisks are included for scores less than one, indicative of concentration

patterns related to a strong influence of size, when we consider large and small firms separately, both geographical location and urbanization levels tend to show systematic patterns of concentration in the SOM, which means that firms with those characteristics tend to have a largely similar performance.

\subsection{SOM analysis of efficient and super-efficient firms}

The final part of this section connects the high-dimensional SOM analysis presented above with an alternative approach of obtaining and using composite indices. The first step is to employ a straightforward efficiency analysis (Sect. 5.4), followed by a multivariate data reduction analysis (Sect. 5.5).

First, we carry out an exploration in the spirit of the SOM approach presented before, but now the variable we map onto the SOM is a quantitative index of performance derived from (a new variant of) Data Envelopment Analysis (DEA). DEA finds its origin in activity analysis, and more specifically in multi-product linear programming 
analysis (see Charnes et al. 1978; Caragliu et al. 2011). It has found a great diversity of business applications all over the world. Its main idea is to find a numerical expression (based on a performance score ranging from 0 to 1 , with 1 being the highest score or the highest efficiency level). We refer, for details, to Suzuki et al. (2010); Suzuki et al. (2011) for spatial DEA applications, viz. to smart infrastructures and to smart regions.

Application of DEA by means of the standard CCR-I method (see Charnes et al. 1978) to our sample of 60 firms - with a further subdivision into their size over the period 2008-leads to the results presented in Appendix C. It turns out that most of the large firms and SMEs belong to the category of efficient firms (which means that they are all located on the efficiency frontier), while for all others there is still scope for an improvement of their performance. But this does mean that it is equally easy for their business to maintain its position or to improve its future position. Thus, by analyzing their scope for marginal improvement efforts what is called 'super-efficiency analysis' may be carried out (for more details on DEA, see Suzuki and Nijkamp 2011; Nijkamp and Suzuki 2009; Caragliu et al. 2011). This leads to a complete ranking of all firms considered, including the ones which have an efficiency score 1.

The super-efficient DEA results show much more variation over the entire set of efficient large firms and SMEs, which essentially means that, in the long run, there is ample space for improvement among all firms. Thus, the use of DEA allows an informed discussion on the relative achievement levels of all firms, in particular since this analysis offers clear information on the strong points of a firm, as well on the weak points that need due care.

The numerical DEA results- both the standard CCR-I and the super-efficient DEA results - allow us to apply a SOM analysis again. In this way, we may characterize different regions of the SOM according to high or low performance, based on the standard DEA index and the super-efficient index. These results are given in Fig. 6.

Figure 6 a divides the firms into those with an efficiency score of 1 (dark) and those below that level (white). When, as above, we calculate the dispersion measure for those firms with a score of 1 , we obtain 0.97 , which implies they do not tend to be closer to each other than the average. Still, if we compute the measure for large and small firms, we obtain 0.59 and 1.05; this means that, once we take size into account, large firms with a score of one do tend to locate near to each other on the SOM. This is rather in line with the results in Tables 1 and 2: large firms show common characteristics and tend to locate in similar regions of the statistical space.

Figure $6 \mathrm{~b}$ presents the map based on a super-efficient DEA in which the index has been plotted along gradient from white (lower values) to dark (higher ones). In this case, it is easier to derive some patterns: the upper left corner shows the lightest colors while, as one moves down-right, the colors darken, although in a more fuzzy fashion. This implies that the former region of the map may be identified with low performance scores, while the latter displays higher ones and, in this sense, is the winner area of the SOM.

As a complement to Fig. 6a and b, c displays the component planes of the performance variables used to train the SOM. As explained in Sect. 3, the planes of a SOM are the representation of the values of each of the variables onto the map. They show the distribution of that component over the trained network, allowing us to identify regions of high and low values of the variable concerned. 


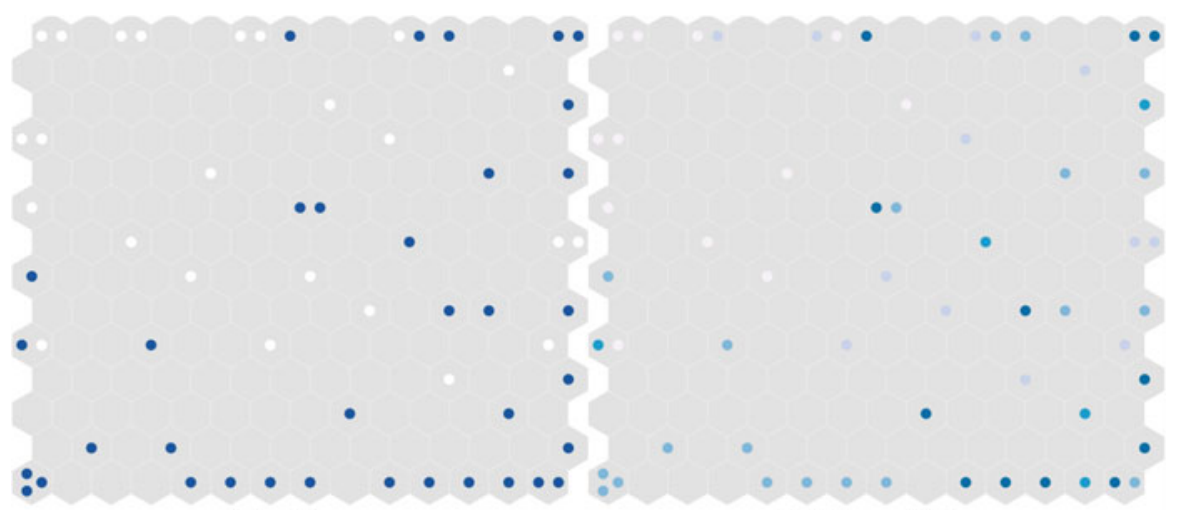

(a) Efficency

(b) Super-efficiency
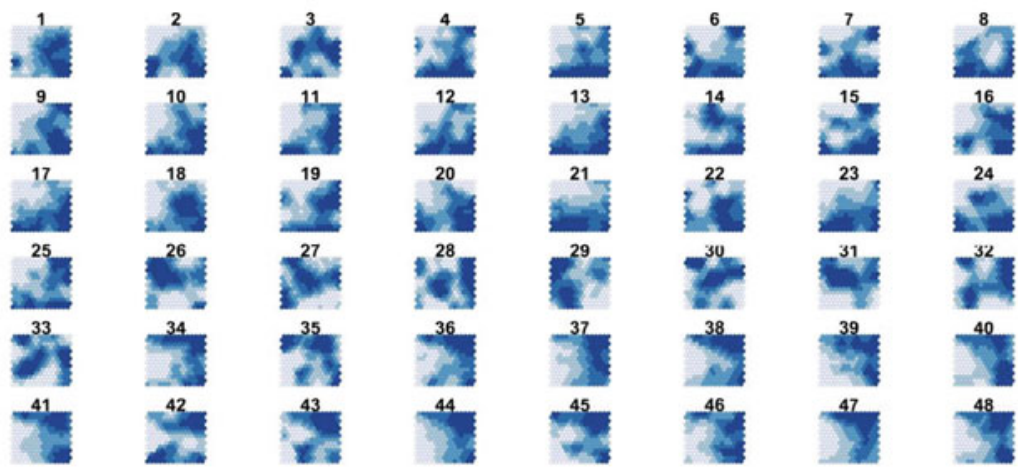

(c) Planes

Fig. 6 Distribution of DEA scores and performance planes. c Please see footnote 10. In particular, the footnote should refer to Table 4 in Appendix A

Given the characteristics of the database, each plane ${ }^{10}$ shows the areas of the SOM with high (dark) and low (white) levels of that factor of performance, dark always implying a better performance. As an illustration, plane number 1 displays the distribution of values of the variable ('increase in revenue'). We can observe how the lowest ones (white) appear in the upper-left part of the SOM, which in turn is the area where the firms with low efficiency and low super-efficiency scores also appear to be located; on the contrary, the highest values may be found on the opposite side of the SOM, the lower right area, which in this case also coincides with the location of some of the firms with high efficiency scores.

Two main conclusions can be drawn from the picture. On the one hand, it offers a good visualization of the complexity embedded in the concept of performance: if all the variables were distributed the same way, it would imply that a high-dimensional analysis is not needed, because each could be representative of the general behavior.

\footnotetext{
10 The planes in Fig. 6c are labeled with a number (1-48) for reasons of lack of space. For some examples of corresponding variables, the reader is referred to Appendix A.
} 
Clearly, high values of each variable are distributed in very diverse ways across the SOM, justifying the approach presented in this paper. On the other hand, there are some characteristics that apply to the majority of the planes. As an example, most of the lowest values (white) tend to be located in the left and upper-left part; although high values (dark) distribute in more varied ways, in most cases, they tend to be located in the lower right-hand region of the map. Such patterns reconcile the SOM approach with the one derived from the DEA analysis which was based on a single composite index and may be seen as a robustness check for both results. We may thus conclude that the DEA analysis supports the SOM results.

\subsection{A multivariate approach to SOM}

Finally, it may be important to explore the results of a multivariate analysis of the massive volume of data in our SOM experiment. The large amount of data in our investigation may incorporate quite considerable dependency among the various variables. To avoid an unwanted bias in our SOM analysis, it is therefore interesting to apply a Principal Component Analysis (PCA) to each of the 8 clusters in the regional data set and to each of the 3 clusters in the firm data set (see also Fig. 2). The SOM can next be applied to the main orthogonal components identified in the PCA. The results are concisely presented in Appendix B. They show a high degree of similarity to those presented in Figs. $3 \mathrm{~b}$ and 4. This implies that our original SOM analysis leads to robust results, which are also supported by a PCA.

\section{Retrospective and prospective remarks}

This paper has demonstrated that systemic complexity in space needs a wealth of data to be explored. Cognitive approaches like SOM analysis may be extremely helpful in identifying interesting and novel patterns in high-dimensional data sets of SPM initiatives of business firms.

In the empirical part of our study, we looked at the issue of firm performance and regional effects from an exploratory perspective, using the SOM as the main methodology and complementing it with other approaches, such as DEA and PCA. In doing so, we sought to shed some light on the main patterns across Dutch firms in terms of their performance in distinct regions, as well as on the drivers that determine such outcomes.

The results point to the size of the firm as the main variable behind the distribution of business performance; firms in the same size category appear to locate in the same regions of the SOM, implying a high degree of similarity. Other variables such as regional location or degree of urbanization do not show such strong systematic patterns; however, once the size is taken into account, regional effects show up in various provinces (e.g., Limburg and Utrecht), and the degree of urbanization also shows some agglomeration patterns in the SOM, suggesting that firms in areas which are equally urbanized tend to have a similar profile in terms of business performance.

Open Access This article is distributed under the terms of the Creative Commons Attribution Noncommercial License which permits any noncommercial use, distribution, and reproduction in any medium, provided the original author(s) and source are credited. 


\section{Appendix A: Overview of general micro- and macro- databases}

This Appendix offers a concise overview of the main categories of variables used in our study, both the spatial variables (Table 3) and the firm-specific variables (Table 4).

Table 3 Regional and location-specific data (2008)

\begin{tabular}{|c|c|}
\hline 8 Cluster indicators & Type of indicators \\
\hline Creative Capital (CC) (60 variables) & $\begin{array}{l}\text { High education and institutions } \\
\text { Meeting points/relations } \\
\text { Breeding places (creative clusters) } \\
\text { Creative professionals/talent } \\
\text { Multicultural neighborhoods/ good quality of place }\end{array}$ \\
\hline Human Capital (HC) (60 variables) & $\begin{array}{l}\text { Economically active population } \\
\text { Number of households } \\
\text { Proportion of employees in sectors } \\
\text { Population density } \\
\text { GDP } \\
\text { Population }\end{array}$ \\
\hline Economic Capital (EC) (60 variables) & $\begin{array}{l}\text { Number of financial sources } \\
\text { Number of new businesses registered in reference year } \\
\text { Total number of firms } \\
\text { Birth-rate businesses } \\
\text { Number of vacancies }\end{array}$ \\
\hline Knowledge Capital (KC) (50 variables) & $\begin{array}{l}\text { Number of patents } \\
\text { Investment climate: innovation } \\
\text { Investment climate: market competition } \\
\text { Total number of innovators with related products } \\
\text { and/or process innovations } \\
\text { Number of highly-educated employees }\end{array}$ \\
\hline Social Capital (SC) (50 variables) & $\begin{array}{l}\text { Rapport score living conditions } \\
\text { Number of care and nursing homes, hospitals \& } \\
\text { service apartments } \\
\text { Restaurants } \\
\text { Number of post offices } \\
\text { Diversity of religions } \\
\text { Hospitals and health centres }\end{array}$ \\
\hline Technological Capital (TC) (30 variables) & $\begin{array}{l}\text { Percentage of households with Internet access at home } \\
\text { Number of local units manufacturing ICT products } \\
\text { Proportion of households with broadband access } \\
\text { Number of DigiD-owners } \\
\text { Telephone mainlines per capita }\end{array}$ \\
\hline
\end{tabular}


Table 3 continued

\begin{tabular}{ll}
\hline 8 Cluster indicators & Type of indicators \\
\hline Cultural Capital (CLC) (50 variables) & Total number of libraries and book loans \\
Number of cinemas \\
Number of theatres \\
Number of museums \\
Number of recreation places \\
Connectivity \& Infrastructure (CF) (50 variables) & Number of public transport systems \\
& Mobility of people and goods/services \\
& Traffic density \\
& Travel time between living areas and work \\
& Number of runways at airports \\
\hline
\end{tabular}

Table 4 Business performance data (2008)

\begin{tabular}{ll}
\hline 3 Cluster indicators & Some examples of indicators \\
\hline High Result Orientation (HRO) (16 variables) & Higher quality \\
& Higher turnover \\
& More innovativeness \\
& Decrease in costs \\
& Higher pro-activity \\
High Quality Business (HQB) (16 variables) & Higher operational efficiency \\
& Better process orientation \\
& Better knowlegde sharing and information \\
& exchange between organisational units \\
& More effective management control \\
& Better quality performance information \\
& More clarity for people about their roles and goals \\
Better Understanding Strategy (BUS) (16 variables) & Better understanding of the strategy by people \\
& Higher employee satisfaction \\
& Better strategic planning process \\
More clarity for people about their roles and goals
\end{tabular}

\section{Appendix B: Integration of SOM and PCA}

In this Appendix, we present an experiment in which we combine the results from a Principle Component Analysis (PCA) with the SOM framework. The main idea is that we use a PCA to extract the main indicators in each cluster of the model (see Fig. 2), and next we employ these main factors as the input data for the SOM, which we then run in a similar fashion as in previous cases. These results are mapped out in Fig. 7. 
Fig. 7 SOM based on PCA (spatial factors)

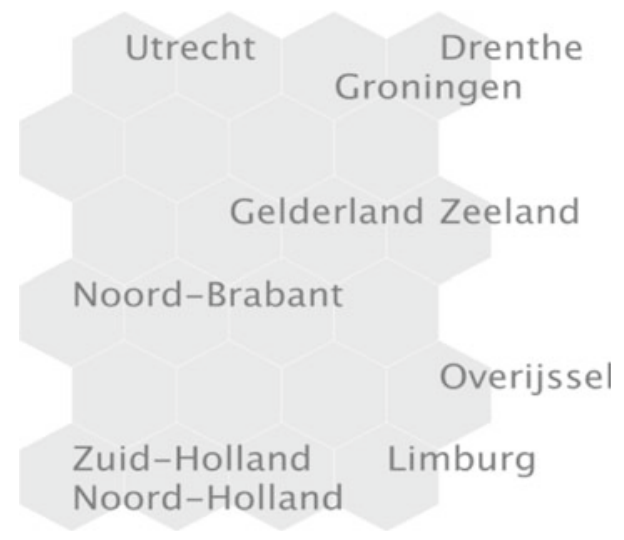

Figure 7 represents the analog of Fig. 3a in the present paper; the different provinces have been used as observations to feed an algorithm, but now the attribute data are not the long list of raw indicators but the main factors obtained after applying PCA to this raw data set, following the model outlined in Sect. 4. The rationale behind this approach is twofold: on the one hand, it serves as a robustness check of the results from Sect. 5, to explore how variations of the data might affect the final map; on the other hand, using the main factors of each cluster implies that each of the model's clusters are given the same weight, ${ }^{11}$ which may serve as a test of the model suggested when compared with the raw results.

In order to ease the interpretation, only the regions have been labeled in Fig. 7. Before proceeding with the comparison, it is also important to remark that even if the results were similar, the new map does not need to be exactly the same as the previous one. The reason resides in the heuristic nature of the SOM algorithm, which may start assigning different random values that result in an overall different configuration of the observations.

A key aspect that deserves attention is the internal configuration and the relationships of the different observations, not particularly their location on the map. Thus, in comparing both maps (Figs. 3a and 7), the conclusion is that most of the bilateral associations between provinces are maintained across the two complimentary approaches. Clearly, it seems as though the axes have been somehow flipped, but the topological relationships between provinces remain the same: Overijssel, Zeeland, and Drenthe are aligned across one of the edges, even though in one case it is the horizontal edge and in the other it is the vertical one, showing slightly more dispersal when the PCA is used; Utrecht and Noord-Brabant are one more cell away when the PCA is used, but they nevertheless remain at a similar distance, now aligned vertically instead of horizontally; Noord-Holland and Zuid-Holland remain very close to each other in both

\footnotetext{
11 Note that the SOM weights each dimension in the same way, unless it is explicitly stated otherwise. Thus, if there are more indicators for one cluster than for another, as is the case in our experiment, some clusters will be given more importance and others less when it comes to decide on the mapping of the observations.
} 


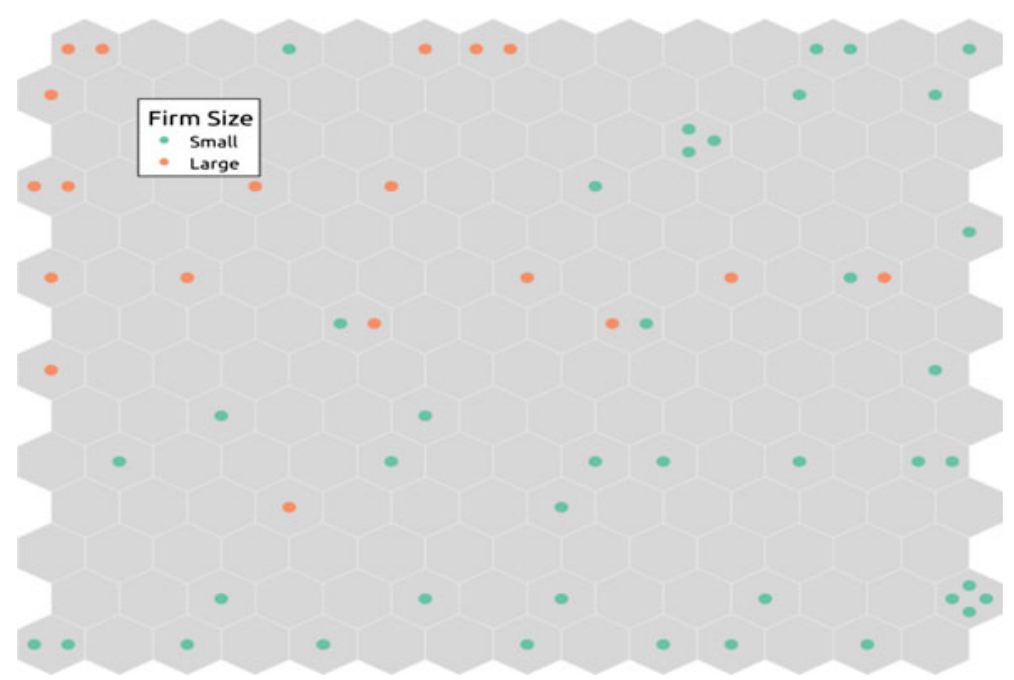

Fig. 8 SOM based on PCA (business performance)

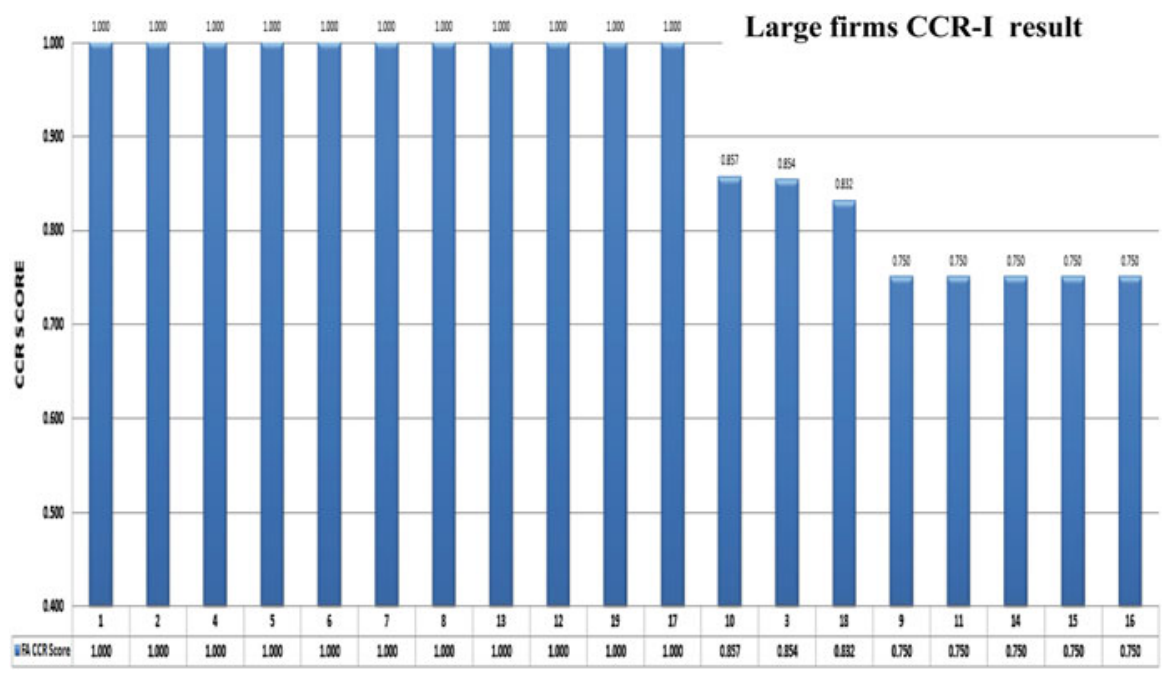

Fig. 9 Standard DEA (CCR-I) score of 19 Dutch large firms (2008)

cases. Only a few provinces change their position more significantly, viz. Limburg and Gelderland.

Next, Fig. 8 displays the analog of Fig. 4 in the paper, but instead of using the raw data, we now employ the independent factors from a PCA. As mentioned in Sect. 5.5, the PCA was computed for three different clusters following the model outlined in Fig. 2, viz. High Result Orientation (HRO), High Quality Business (HQB), and Better Understanding Strategy (BUS). Although the general configuration has somewhat changed (which was to be expected due to the heuristic nature of the SOM algorithm), we can clearly see that the internal relationships between the firms remain 
similar. In particular, the distribution based on size equally exhibits the dramatic split that we observed in the previous case between large and small firms, supporting the conclusions drawn in the main part of the paper.

\section{Appendix C: DEA results for efficient and super-efficient firms}

In this Appendix, we present the empirical results for the DEA approach to analyzing the sample of large and small firms, using both the CCR-1 DEA algorithm and the super-efficiency DEA algorithm (see Figs. 9, 10, 11 and 12).

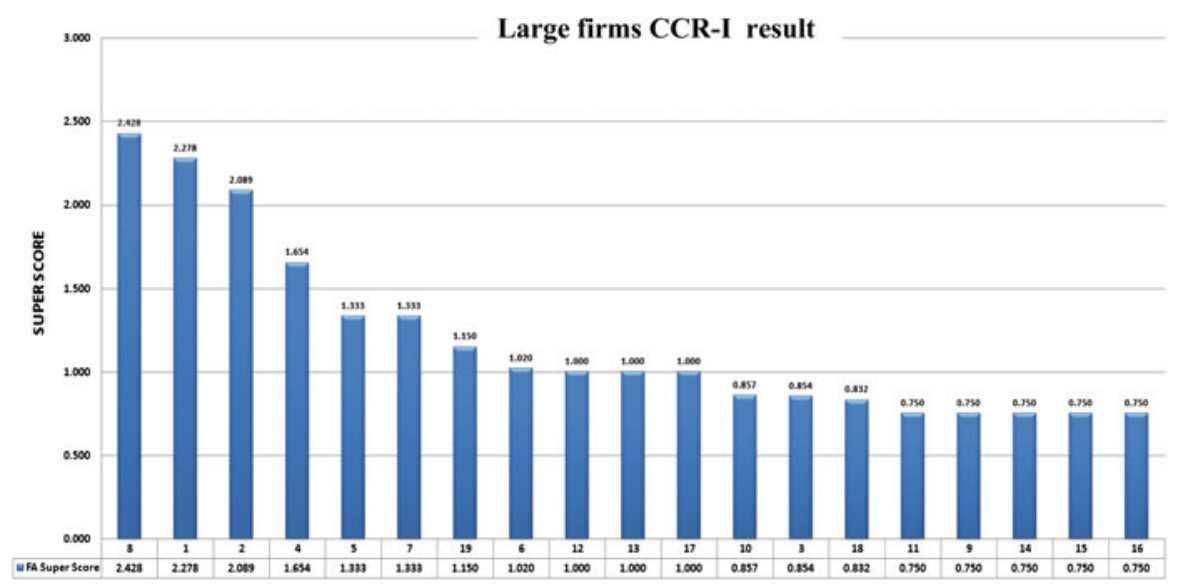

Fig. 10 Super-efficiency score of 19 large firms (2008)

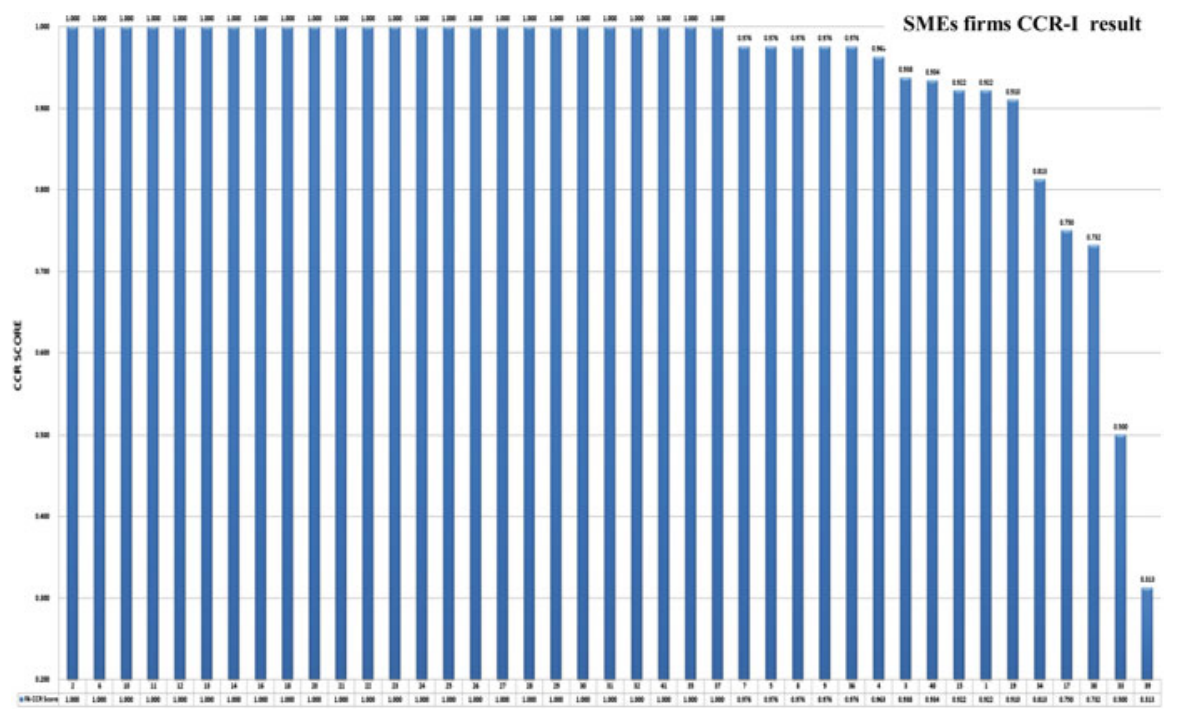

Fig. 11 Standard DEA (CCR-I) score of 41 Dutch SMEs firms (2008) 


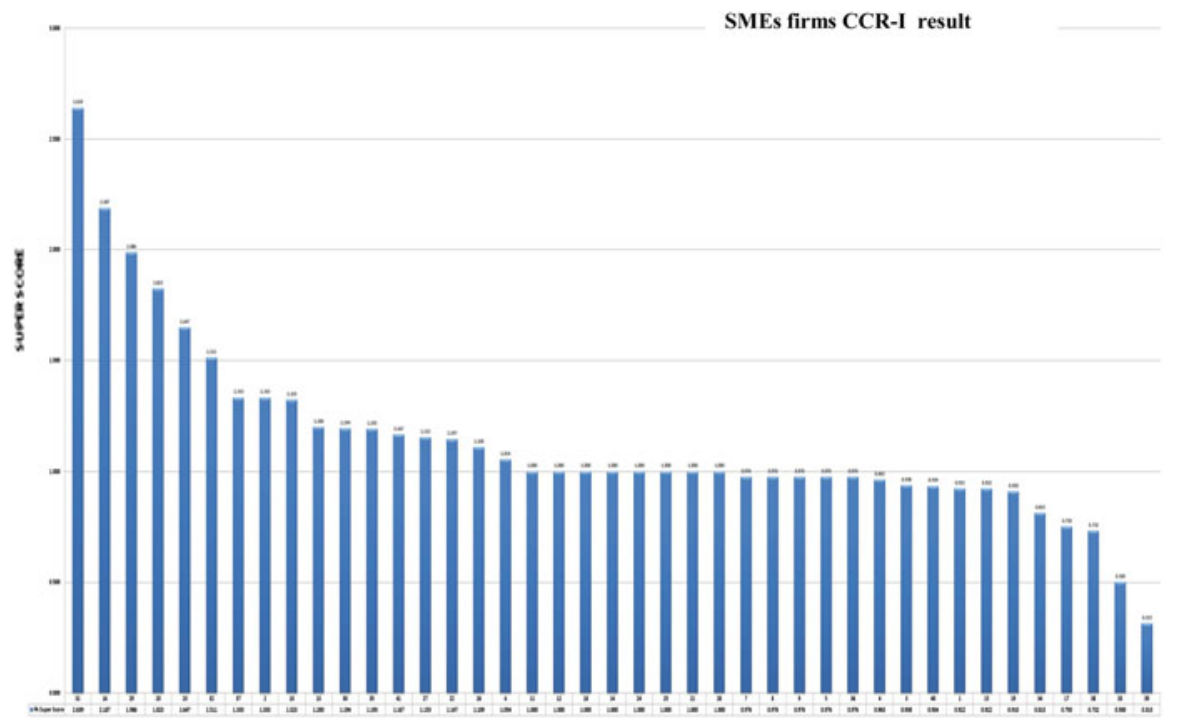

Fig. 12 Super-efficiency score of 41 SMEs firms (2008)

\section{References}

Acs ZJ, de Groot HLF, Nijkamp P (eds) (2002) The emergence of the knowledge economy. Springer, Berlin

Agarwal P, Skupin A (eds) (2007) Self-organizing maps: applications in geographic information science. Wiley, Chichester

Alecke B, Alsleben C, Scharr F, Untiedt G (2006) Are there really high-tech clusters? The geographic concentration of German manufacturing industries and its determinants. Ann Reg Sci 40:19-42

Andersson A (1985) Creativity and regional development. Pap Reg Sci Assoc 56:5-20

Arribas-Bel D, Nijkamp P, Scholten H (2011) Multidimensional urban sprawl in Europe: a self-organizing map approach. Comput Environ Urb Syst 35(4):263-275

Bayliss D (2007) The rise of the creative city: culture and creativity in Copenhagen. Eur Plan Stud 15: 889-903

Bellini E, Ottaviano GIP, Pinelli D, Prarolo G (2008) Cultural diversity and economic performance: evidence from European Regions. In: Paper presented at the 7th European urban and regional studies conference 'Diverse Europe: urban and regional openings, connections and exclusions', Istanbul, 18-21 September 2008

Berry MMJ, Taggart JH (1996) Combining technology and corporate strategy in small high tech firms, strathclyde international business unit, Department of marketing. University of Strathclyde, Glasgow

Bommer M, Jalajas D (2002) The innovation work environment of high-tech SMEs in the USA and Canada. R D Manag 32(5):379-386

Bruinsma FR, Kourtit K, Nijkamp P (2009) An agent-based decision support model for the development of e-services in the tourist sector. Research memorandum 2009-32. Faculteit der Economische Wetenschappen en Bedrijfskunde, Amsterdam

Capello R (2002) Entrepreneurship and spatial externalities: theory and measurement. Ann Reg Sci 36: 387-402

Caragliu A, Del Bo C, Kourtit K, Nijkamp P, Suzuki S (2011) A search for incredible cities by means of super-efficiency data envelopment analysis. Stud Reg Sci (forthcoming)

Charnes A, Cooper W, Rhodes E (1978) Measuring the efficiency of decision making units. Eur J Oper Res 2:429-444 
Cooper SY, Park JS (2008) The impact of 'Incubator' organizations on opportunity recognition and technology innovation in new, entrepreneurial high-technology ventures. Int Small Bus J 26(1):27-56

de Waal AA (2007) Strategic performance management, a managerial and behavioural approach. Palgrave MacMillan, London

de Waal AA, Kourtit K, Nijkamp P (2009) The relationship between the level of completeness of a strategic performance management system and perceived advantages and disadvantages. Int J Oper Prod Manag 29(12):1242-1265

Duranton G, Puga D (2003) Micro-foundations of urban agglomeration economies, NBER Working Paper 9931. National Bureau of Economic Research Washington, DC

Felsenstein D (2002) Do high technology agglomerations encourage urban sprawl? Ann Reg Sci 36(4): 663-682

Fischer MM (2001) Computational neural networks: tools for spatial data analysis. In: Fischer MM, Leung Y (eds) Geocomputational modelling: techniques and applications. Springer, Heidelberg, pp 79-102

Florida R (2002) The rise of the creative class. Basic Books, New York

Florida R (2003) Entrepreneurship, creativity and regional economic growth. In: Hart DM (ed) The emergency of entrepreneurship policy. Cambridge University Press, Cambridge, pp 15-43

Florida R (2004) The flight of the creative class. Basic Books, New York

Forte F, Fusco Girard L, Nijkamp P (2006) Smart policy, creative strategy and urban development. Stud Reg Sci 35(4):947-963

Glaeser E (2004) Review of Richard Florida's The Rise of the Creative Class, unpublished monograph, Harvard University, post.economics.harvard.edu/f aculty/glaeser/papers/Review_Florida.pdf

Jacobs J (1969) The economy of cities. Vintage, New York

Jones-Evans D, Klofsten M (1997) Universities and local economic development: the case of Linkoping. Eur Plan Stud 5(1):77-94

Kohonen T (2001) Self-organizing maps. Springer, Berlin

Kourtit K, de Waal AA (2009) Strategic performance management in practice: advantages, disadvantages and reasons for use. Paper presented at the 2009 performance measurement association conference. University of Otago's School of Business, Dunedin

Kourtit K, Nijkamp P (2011) Creativity and diversity: strategic performance management of high-tech SMEs in Dutch urban areas. In: Kourtit K, Nijkamp P, Stough RR (eds) Drivers of innovation, entrepreneurship and regional dynamics. Springer, Berlin, pp 45-64

Kourtit K, Nijkamp P, Stough R (eds) (2011a) Drivers of innovation, entrepreneurship and regional dynamics. Springer, Berlin

Kourtit K, Nijkamp P, Arribas D (2011b) Smart cities perspective-a comparative European study by means of self-organizing maps. J Innov (forthcoming)

Kourtit K, Nijkamp P, Lowik S, van Vught F, Vulto P (2011c) From Islands of innovation to creative hotspots. J Reg Sci Policy Pract 3(3):145-161

Kohonen T, Honkela T (2007) Kohonen network. Scholarpedia 2(1):1568

Krugman PR (1996) The self-organizing economy. Blackwell, Cambridge

Kumar M, Bowen WM, Kaufman M (2007) Urban spatial pattern as self-organizing system: an empirical evaluation of firm location decisions in Cleveland-Akron PMSA, Ohio. Ann Reg Sci 41(2):297-314

Landry C (2000) The creative city: a toolkit for urban innovators. Earthscan, London

Lee SY, Florida R, Acs ZJ (2004) Creativity and entrepreneurship: a regional analysis of new firm formation. Reg Stud 38:879-891

Lung Y (1988) Complexity and spatial dynamics modelling. From catastrophe theory to self-organizing process: a review of the literature. Ann Reg Sci 22(2):81-111

Matheson B (2006) A culture of creativity: design education and the creative industries. J Manag Dev 25(1):55-64

Mcgranahan M, Timothy W (2007) Recasting the creative class to examine growth processes in rural and urban countries. Reg Stud 41(2):197-216

Moreno R, Paci R, Usai S (2005) Geographical and sectoral clusters of innovation in Europe. Ann Reg Sci 39(4):715-739

Muñiz ASG, Raya AM, Carvajal CR (2010) Spanish and European innovation diffusion: a structural hole approach in the input-output field. Ann Reg Sci 44(1):147-165

Nijkamp P (2008) XXQ factors for sustainable urban development: a systems economics view. Romanian J Reg Sci 2(1):325-342 
Nijkamp P (2009) Regional development as self-organized converging growth. In: Kochendörfer-Lucius G, Pleskovic BB (eds) Spatial disparities and development. The World Bank, Washington, pp 265-281

Nijkamp P, Suzuki S (2009) A generalized goals-achievement model in data envelopment analysis: an application to efficiency improvement in local government finance in Japan. Spatial Econ Anal 4(3): 249-274

Oakey RP (2007) Clustering and the R\&D management of high-technology small firms in theory and practice. J R and Manag 37(3):237-248

Olfert MR, Partridge MD (2011) Creating the cultural community: ethnic diversity versus agglomeration. Spatial Econ Anal 6(1):25-55

Pavitt K (1990) What we know about the strategic management of technology. Calif Manag Rev Spring $17-26$

Peck J (2005) Struggling with the creative class. Int J Urban Reg Res 29(4):740-770

Porter ME (1990) Competitive advantage of nations. Macmillan, London and Basingstoke

Porter ME (2002) Regional foundations of competitiveness. Issues for wales. Paper presented at conference 'Future competitiveness of wales: innovation, entrepreneurship and technology change' on April 3, 2002

Reggiani A, Nijkamp P (eds) (2009) Complexity and spatial networks: in search of simplicity. Springer, Berlin

Shea C (2004) The road to riches? Boston Globe 29 Feb, D1. http://www.boston.com/news/globe/ideas/ articles/2004/02/29/the_road_to_riches/

Skupin A, Agarwal P (2007) Introduction: what is a self-organizing map? In: Agarwal P, Skupin A (eds) Self-organizing maps: applications in geographic information science. Wiley, Chichester, pp 9-21

Skupin A, Hagelman R (2005) Visualizing demographic trajectories with self-organizing maps. GeoInformatica 9(2):159-179

Sonis M, Hewings GJD (1998) Economic complexity as network complication: multiregional input output structural path analysis. Ann Reg Sci 32:407-436

Spielman S, Thill J (2008) Social area analysis, data mining, and GIS. Comput Environ Urban Syst 32(2):110-122

Suzuki S, Nijkamp P (2011) A stepwise-projection data envelopment analysis for public transport operations in Japan. Lett Spatial Res Sci 4(2):139-156

Suzuki S, Nijkamp P, Rietveld P, Pels E (2010) A distance friction minimization approach in data envelopment analysis: a comparative study on airport efficiency. Eur J Oper Res 207:104-1115

Suzuki S, Nijkamp P, Rietveld P (2011) Regional efficiency improvement by means of data envelopment analysis through euclidean distance minimization including fixed input factors: an application to tourist regions in Italy. Pap Reg Sci 90(1):67-89

Tornqvist G (1983) Creativity and the renewal of regional life. Lund Stud Geogr B Hum Geogr 50:91-112

van Geenhuizen M (2007) Modeling dynamics of knowledge networks and local connectedness: a case study of urban high tech companies in the Netherlands. Ann Reg Sci 41(4):813-833

van den Berg GJ (2001) Duration models: specification, identification, and multiple durations. In: Heckman JJ, Leamer E (eds) Handbook of econometrics, vol V. North-Holland, Amsterdam, pp 123-147

Yan J, Thill J (2009) Visual data mining in spatial interaction analysis with self-organizing maps. Environ Plan B Plan Des 36:466-486 